\title{
3D FEM ANALYSIS OF THE CONSTRUCTION PIT FOR A TBM-DRIVEN FLOOD DISCHARGE GALLERY
}

\author{
JÖRG-MARTIN HOHBERG
}

\begin{abstract}
IUB Engineering AG, Eiger House, Belpstrasse 48, 3007 Bern, Switzerland
correspondence: martin.hohberg@iub-ag.ch
\end{abstract}

\begin{abstract}
As one speciality of the Swiss hydraulic engineering tradition, several torrent diversion schemes were undertaken dating from the $18^{\text {th }}$ century, with the aim of using the natural lake as a retention basin. The recent project of flood protection of the lower Sihl valley and the City of Zurich features a gallery of $2.1 \mathrm{~km}$ length with a $6.6 \mathrm{~m}$ inner diameter designed for a $330 \mathrm{~m}^{3} / \mathrm{s}$ free flow, discharging into Lake Zurich in an $\mathrm{HQ}_{500}$ event. After a short presentation of the main features of the project, the paper concentrates on the target construction pit of the TBM drive close to a major railway line at the built-up lakeside.
\end{abstract}

KEYWORDS: Hydraulic engineering, torrent diversion, natural lake, retention basin, flood, flood protection.

\section{Historical Background}

Prolonged heavy rainfall, or the combination of rain pouring into melting snow fields during warm downhill winds (foehn conditions), can suddenly turn peaceful creeks into dangerous torrents, eroding hillsides upstream and depositing extensive gravel fans further downstream, which may block other rivers and permanently raise the valley floor. In medieval times this created malarial swamps and jeopardized the dwellings upstream. Where the gravel bed load discharged into a lake, this risk did not occur as long as the lake was deep enough.

The earliest man-made diversion scheme in Switzerland was that of the Kander torrent into Lake Thun. During 1711-1714 a gallery was dug in molasse conglomerate, which soon collapsed however, due to backward erosion of the invert [1]. 300 years later, the cut looks like a natural canyon, see Figure 1 . The problem with this pioneering project was that the additional influx led to a rise of the water table of the lake and increased the risk of flooding the city of Thun. The problem was solved, when a $1.2 \mathrm{~km}$ long flood protection gallery of a clear $5.4 \mathrm{~m}$ diameter was opened in 2009 [2].

After other river diversions - Linth 1807-1816, Glatt 1813-1830 (incl. a gallery), Aare/Jura 1868-1891 plans were made in 1865-1897 also to divert the Sihl into Lake Zurich. The most recent large flood in Zurich occurred in 1910, Figure 2 (left).

Although since 1937 a hydropower station (Etzelwerk) is regulating the Sihl lake, the current value at risk due to an inundation of Zurich is estimated to be CHF 20 million per year. This is because the Sihl flows through the outskirts of Zurich and passes under Zurich's main railway station, where it joins the Limmat river - a geographical situation similar to Dresden (Saxonia), where the flood of 2002 caused $€ 6,200$ million in damage. Quite a similar loss is estimated for an extreme Sihl flood.

\section{The Sihl FLOOD PROTECTION Gallery ThaLWIL}

Several remedies were studied, including a larger discharge of the Etzelwerk during its current refurbishment ("Kombilösung" in Figure 2 (right)); but the preferred solution is the separate "Stollen Thalwil" to be built over a time period to 2023 with an investment of CHF 130 million.

Starting from an intake structure situated at the exterior bank in a river bend downstream of a recently built rake against driftwood, the gallery will have a length of $2.1 \mathrm{~km}$, a clear diameter of $6.4 \mathrm{~m}$ and a free-flow design capacity of $330 \mathrm{~m}^{3} / \mathrm{s}$. This sufficiently limits the damage in Zurich in case of a $\mathrm{HQ}_{500}$ $\left(600 \mathrm{~m}^{3} / \mathrm{s}\right)$.

An important constraint is the future Zimmerberg railway base tunnel to be overpassed, necessitating a kink in slope of $1.2 \%$ and $3.3 \%$ respectively, Figure 3 and Figure 4

The outlet structure will be placed at the shore of Lake Zurich in close proximity to a major railway line, an existing water purification plant and a public bathing beach. In order to avoid strong currents, the mouthpiece of the outlet will be hidden $3 \mathrm{~m}$ under the water surface and extend $90 \mathrm{~m}$ into the lake, as a concrete box-section founded on piles.

\subsection{GeOlOGY}

The gallery will traverse the Upper Freshwater Molasse (OSM) with an almost horizontal stratification of normal- and fine-grained sandstone, siltstone and marl. The latter may exhibit very low strength in the presence of water. Although the molasse rock itself has a low water permeability, decompression joints are expected to run parallel to the level course. The 

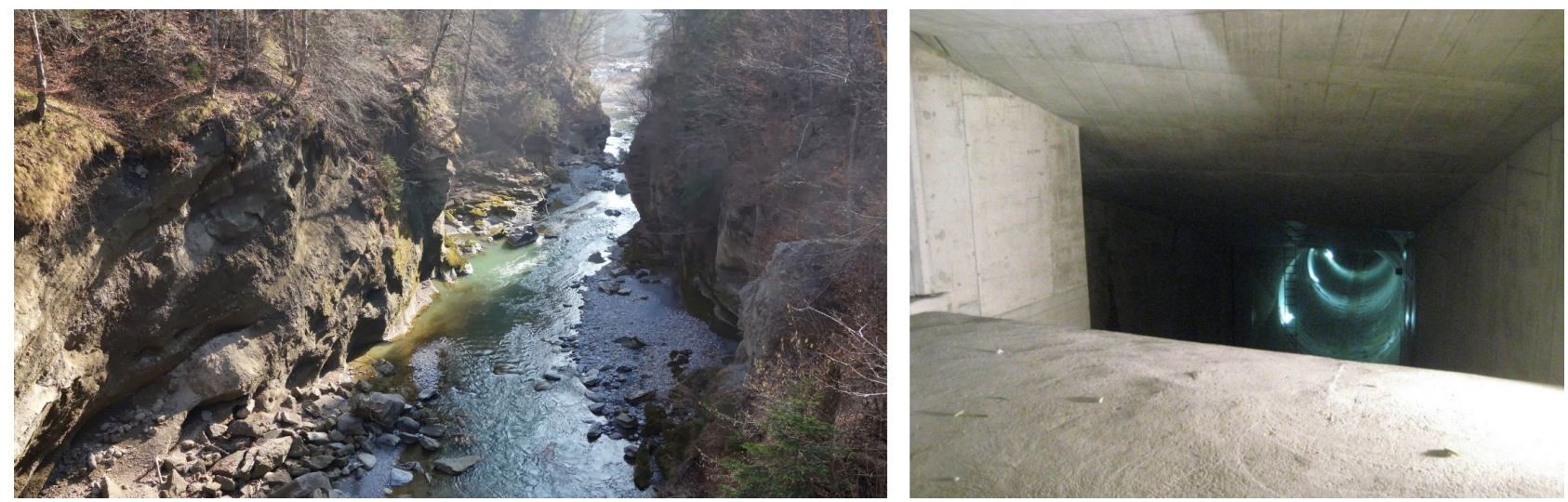

Figure 1. The Kander canyon today (left) with the flood relief gallery (right) in the City of Thun [2].
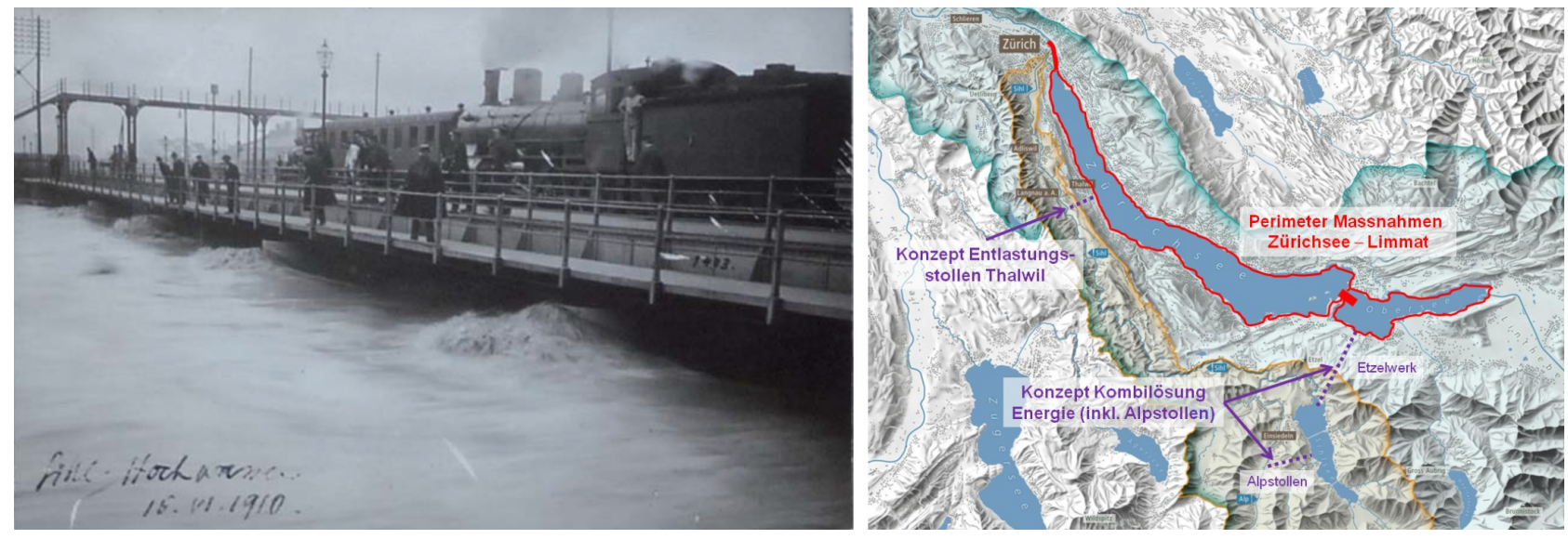

Figure 2. The Sihl at Zurich main railway station in 1910 (left) and alternative flood relief projects (right) 3].

OSM is overlain by moraine deposits. All the rock properties are summarized in Table 1

The top 4-6 $\mathrm{m}$ of the OSM stratum are supposed to be weathered rock with low properties close to those of pure marl, Figure 5 . The moraine is shown in green. Note the main railway line on the left-hand side.

\subsection{Geotechnical models}

For the analysis of the gallery proper, the OSM stratification was homogenized to an equivalent stiffness according to the relative percentages of the strata, giving an elastic modulus of $1.5 \mathrm{GPa}$. For the MohrCoulomb model a $40^{\circ}$ friction angle and a $2.5 \mathrm{MPa}$ cohesion were adopted. The drainage of the rock during the TBM drive was simulated by lowering and re-raising the water table.

For the analysis of the outlet construction pit, several scenarios were investigated with differing approximations of the ground properties listed in Table 2

Set A assumes characteristic values located about half-way between the mean and the inferior values ("cautious mean values"). Set B1 and B2 distinguish between the rock matrix and the low values in horizontal sedimentation planes (multi-laminate model). Finally, set $\mathrm{C}$ is a pessimistic combination of residual values ("ubiquitous joints").

The influence of ground water was neglected here, assuming full drainage due to excavation. A nonassociated flow rule was adopted throughout, with $\psi=\varphi-30^{\circ}$.

\section{The three dimensional Finite ELEMENT MODEL}

From the beginning it was clear that a 3D model with some reasonable resolution (say $\leq 50 \mathrm{~cm}$ element size) would just about allow a symmetrised representation of the construction pit. Brick elements with 8 nodes in an enhanced assumed strain (EAS) formulation of Z-Soil $^{\circledR}$ were used 4 .

The largest model of $70 \times 30 \mathrm{~m}$ length and width comprises 624'000 DoF, a smaller one still 464'000 DoF, Figure 6. The latter is sufficient to study the behaviour of the gallery underneath the railway line, while the larger one is necessary to check the overall stability of the construction pit.

The meshing of the geological strata together with the circular geometry of the gallery demanded some compromises, which might be avoided by meshing the gallery part and the construction pit part separately and by tying both meshes together in a global constraint approach. 


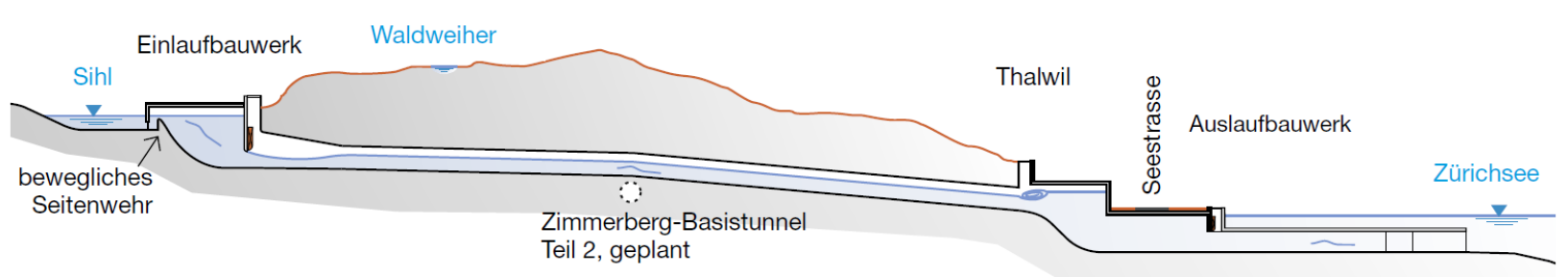

Figure 3. Longitudinal section of the gallery [3].

\begin{tabular}{lllll}
\hline Parameter & Fine sandstone & Siltstone & Marl & Moraine \\
\hline Specific weight $\gamma$ & $26.3 \pm 0.3 \mathrm{kN} / \mathrm{m}^{3}$ & $26.4 \pm 0.2 \mathrm{kN} / \mathrm{m}^{3}$ & $23.8 \pm 1.0 \mathrm{kN} / \mathrm{m}^{3}$ & $22 \mathrm{kN} / \mathrm{m}^{3}$ \\
\hline Friction angle $\varphi$ & $58.8 \pm 4.6^{\circ}$ & $55.3 \pm 5.4^{\circ}$ & $33^{\circ}$ & $34^{\circ}$ \\
\hline Cohesion $c^{\prime}$ & $7.0 \pm 2.2 \mathrm{MPa}$ & $3.7 \pm 0.9 \mathrm{MPa}$ & $21 \mathrm{MPa}$ & $0.005 \mathrm{MPa}$ \\
\hline Residual friction & $50.8 \pm 3.7^{\circ}$ & $47.0 \pm 1.0^{\circ}$ & $23.0 \pm 12.4^{\circ}$ & \\
\hline RF Direct shear & & $26.0 \pm 4.2^{\circ}$ & $19.8 \pm 5.9^{\circ}$ & \\
\hline Residual cohesion & $(1.4 \pm 0.2 \mathrm{MPa})$ & $(1.5 \pm 0.3 \mathrm{MPa})$ & $(0.8 \pm 0.5 \mathrm{MPa})$ & \\
\hline RC Direct shear & & $0.023 \pm 0.004 \mathrm{MPa}$ & $0.038 \pm 0.015 \mathrm{MPa}$ & \\
\hline $\mathrm{E}_{50}$ modulus & $12.7 \pm 1.7 \mathrm{GPa}$ & $9.6 \pm 3.0 \mathrm{GPa}$ & $0.17 \pm 0.12 \mathrm{GPa}$ & $0.050 \mathrm{GPa}$ \\
\hline V modulus & $14.3 \mathrm{GPa}$ & $3.8 \mathrm{GPa}$ & $0.6 \mathrm{GPa}$ & $0.05 \mathrm{GPa}$ \\
\hline${ }^{*}$ Frona
\end{tabular}

${ }^{*}$ From in situ dilatometer test.

TABLE 1. Rock properties (triaxial and direct shear).

\begin{tabular}{lllll}
\hline Set A & OSM & Weathered (marl) & Moraine & Man-made fill \\
\hline Specific weight $\gamma$ & $26.4 \mathrm{kN} / \mathrm{m}^{3}$ & $23.8 \mathrm{kN} / \mathrm{m}^{3}$ & $22 \mathrm{kN} / \mathrm{m}^{3}$ & $18 \mathrm{kN} / \mathrm{m}^{3}$ \\
\hline Friction angle $\varphi^{\prime}$ & $34^{\circ}$ & $16^{\circ}$ & $34^{\circ}$ & $29^{\circ}$ \\
\hline Cohesion $c^{\prime}$ & $480 \mathrm{kPa}$ & $120 \mathrm{kPa}$ & $10 \mathrm{kPa}{ }^{*}$ & $5 \mathrm{kPa}$ \\
\hline E modulus & $3,800 \mathrm{MPa}$ & $600 \mathrm{MPa}$ & $50 \mathrm{MPa}$ & $5 \mathrm{MPa}$ \\
\hline \hline Set B1 & OSM & Weathered (marl) & Moraine & Man-made fill \\
\hline Specific weight $\gamma$ & $26.4 \mathrm{kN} / \mathrm{m}^{3}$ & $23.8 \mathrm{kN} / \mathrm{m}^{3}$ & $22 \mathrm{kN} / \mathrm{m}^{3}$ & $18 \mathrm{kN} / \mathrm{m}^{3}$ \\
\hline Friction angle $\varphi^{\prime}$ & $46^{\circ} / 23.9^{\circ}$ & $16.9^{\circ} / 16.8^{\circ}$ & $34^{\circ}$ & $29^{\circ}$ \\
\hline Cohesion $c^{\prime}$ & $960 / 21 \mathrm{kPa}$ & $240 / 22.7 \mathrm{kPa}$ & $10 \mathrm{kPa}{ }^{*}$ & $5 \mathrm{kPa}$ \\
\hline E modulus & $3,800 \mathrm{MPa}$ & $600 \mathrm{MPa}$ & $50 \mathrm{MPa}$ & $5 \mathrm{MPa}$ \\
\hline \hline Set B2 & OSM & Weathered $($ marl) & Moraine & Man-made fill \\
\hline Specific weight $\gamma$ & $26.4 \mathrm{kN} / \mathrm{m}^{3}$ & $23.8 \mathrm{kN} / \mathrm{m}^{3}$ & $22 \mathrm{kN} / \mathrm{m}^{3}$ & $18 \mathrm{kN} / \mathrm{m}^{3}$ \\
\hline Friction angle $\varphi^{\prime}$ & $46^{\circ} / 22^{\circ}$ & $11^{\circ} / 14^{\circ}$ & $34^{\circ}$ & $29^{\circ}$ \\
\hline Cohesion $c^{\prime}$ & $1,200 / 19 \mathrm{kPa}$ & $300 / 23 \mathrm{kPa}$ & $10 \mathrm{kPa}{ }^{*}$ & $5 \mathrm{kPa}$ \\
\hline E modulus & $1,500 \mathrm{MPa}$ & $110 \mathrm{MPa}$ & $50 \mathrm{MPa}$ & $5 \mathrm{MPa}$ \\
\hline \hline Set C & OSM & Weathered $($ marl) & Moraine & Man-made fill \\
\hline Specific weight $\gamma$ & $26.4 \mathrm{kN} / \mathrm{m}^{3}$ & $23.8 \mathrm{kN} / \mathrm{m}^{3}$ & $22 \mathrm{kN} / \mathrm{m}^{3}$ & $18 \mathrm{kN} / \mathrm{m}^{3}$ \\
\hline Friction angle $\varphi^{\prime}$ & $30^{\circ}$ & $20^{\circ}$ & $34^{\circ}$ & $29^{\circ}$ \\
\hline Cohesion $c^{\prime}$ & $40 \mathrm{kPa}$ & $25 \mathrm{kPa}$ & $10 \mathrm{kPa}{ }^{*}$ & $5 \mathrm{kPa}$ \\
\hline E modulus & $3,800 \mathrm{MPa}$ & $600 \mathrm{MPa}$ & $50 \mathrm{MPa}$ & $5 \mathrm{MPa}$ \\
\hline${ }^{*}$ Accounting tabilzing & & &
\end{tabular}

TABLE 2. Geotechnical assumptions. 


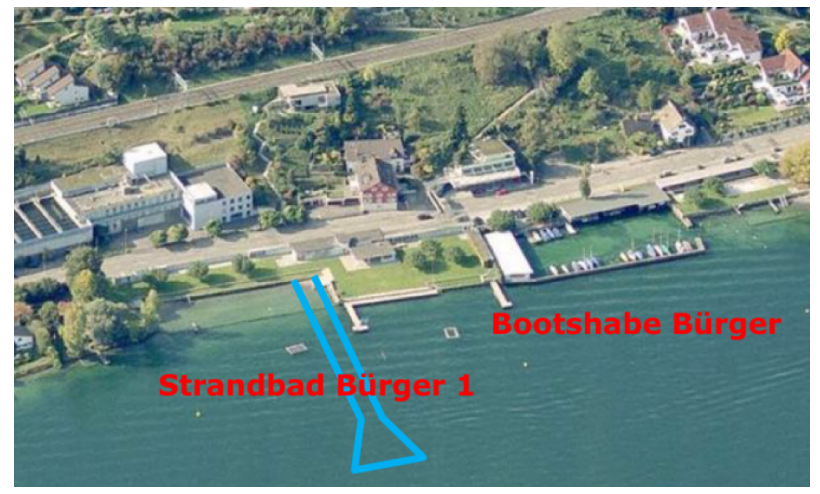

FiguRE 4. Situation at the lake site (outlet structure in blue) 3 .

\subsection{Serviceability limit state (SLS)}

The concern of the railway line operator is the stability of the tracks during construction of the gallery. This is checked at serviceability level in the medium-size model. The gallery is assumed to remain unlined under the railway tracks while the TBM is slowly advancing to the disassembly point. But even with the very low stiffnesses and low strengths of parameter set B2 (Table 2) the absolute displacements do not exceed $1.3 \mathrm{~mm}$ (Figure 7).

The results do not look alarming at all, except for the fact that the displacements are increasing substantially during the last few meters of ground at the excavation face before the gallery daylights into the outlet construction pit. This indicates an unfavourable interaction of the gallery with the slope above the portal wall, which is due to the fact that the thickness of the loose overburden (man-made fill, moraine and weathered OSM) is increasing towards the portal.

\subsection{HAZARD SCENARIO OF DEEP-SEATED PIT FAILURE}

The construction pit was dimensioned with conventional limit equilibrium analysis software, featuring passive nailing and shotcrete sealing of the surface. In the medium-size model the nails are represented in a discrete fashion, while in the large-size model the cohesion of the overburden was simply increased by $5 \mathrm{kPa}$ ("smeared nailing effect").

The large-size model is used to check the stability of the longitudinal construction pit walls. In predominantly elastic behaviour the inward pointing corner of the pit stabilizes the walls (Figure 7). With the isotropic low parameters of set $\mathrm{C}$, however, this stabilizing effect diminishes and the analysis indicates the risk of total collapse of the construction pit already during its excavation, long before the arrival of the gallery bore (Figure 8).

\subsection{HAZARD SCENARIO OF FACE SLOPE FAILURE}

With a slightly better friction angle and the high cohesion of parameter set A the construction pit does not fail, but a potentially critical situation arises during punching of the portal wall (Figure 9).

Generally, a $\mathrm{FoS}=3.0$ would be more than sufficient, but it should be noted that the predicted strength parameters in the sedimentation planes are still lower than those of the matrix divided by three. It was thus concluded that a reliable analysis of the ultimate limit state (ULS) demands an anisotropic model.

\section{Ultimate limit state (ULS) of THE GALLERY}

The following two analyses use a multi-laminate model, which combines a Mohr-Coulomb failure criterion for the matrix with a separate criterion for the horizontal stratification. The strength parameters are those of set B1 (Table 2).

\subsection{REDUCtion OF BOth FRICTIONAL AND COHESIVE STRENGTH}

The hazard scenario is that of sandstone plates detaching from the gallery crown ("coffin lid"), which would jeopardize the TBM advancement and might eventually progress upwards to the surface. Because the safety margin of the loose overburden is inferior to that in the OSM, such an analysis needs to exempt the overburden from the $\varphi$-c reduction. The failure nevertheless occurs in the slope rather than in the gallery crown (Figure 10.

Further refinement of the model, i.e. by incorporating the shotcrete as plate elements, is not attractive (in terms of DoF) and even illusive, as the plate elements could not rupture in shear. Note also that a FoS $=1.46$ on the characteristic strength is not sufficient to cover the wide spread of the lowest residual values, even though the partial safety factor $\gamma_{c}=1.5$ for cohesion, as stipulated by the Swiss code SIA 167 , is almost attained (while exceeding $\gamma_{\varphi}=1.2$ for friction by far).

\subsection{Reduction of COHESIVE STREnGth, STARTING FROM DESIGN FRICTION ANGLES}

Hence, an alternative method was used for ULS assessment, starting from the design values of the lowest residual friction angle $\left(\gamma_{\varphi}=1.2\right)$ : moraine $\varphi_{d}^{\prime}=29.3^{\circ}$, $\operatorname{marl} \varphi^{\prime}{ }_{d}=9.2^{\circ}$, OSM $\varphi^{\prime}{ }_{d}=40.8^{\circ}$ resp. $\varphi^{\prime}{ }_{d}=18.6^{\circ}$ in sedimentation planes. All friction angles are kept constant, while the cohesion is reduced by $c_{k} / F_{O} S_{c} \rightarrow c_{d}$ using the option of pure c-reduction in Z-Soil ${ }^{\circledR}$ (Figure 11. If the analysis converges for $F_{0} S_{c} \rightarrow \gamma_{c}=1.5$, the safety factors for both friction and cohesion would be satisfied.

As the convergence fails prematurely at $F o S_{c}=1.18$, the unlined gallery is unsafe 


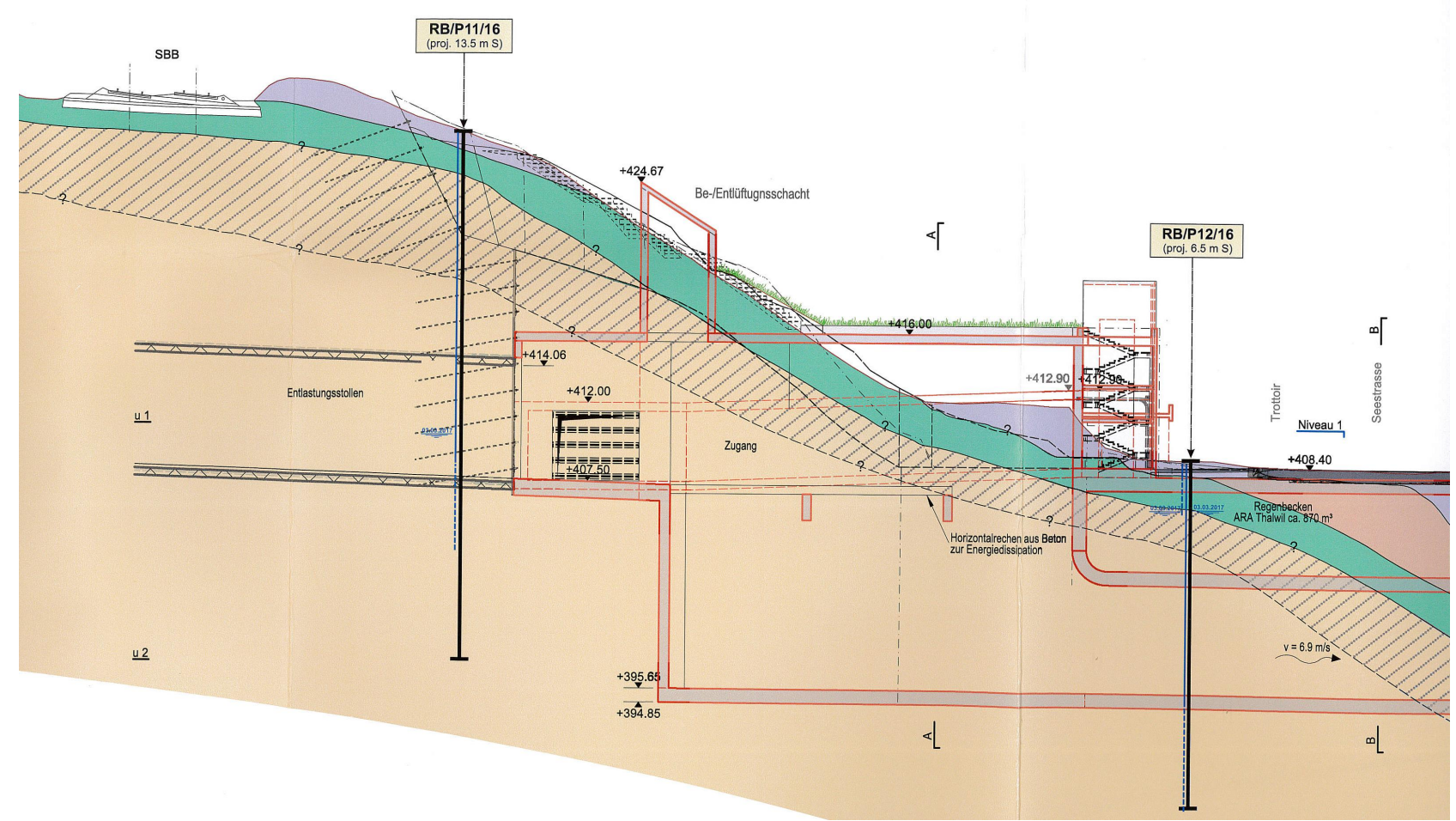

FiguRE 5. Geological profile through the planned outlet structure.
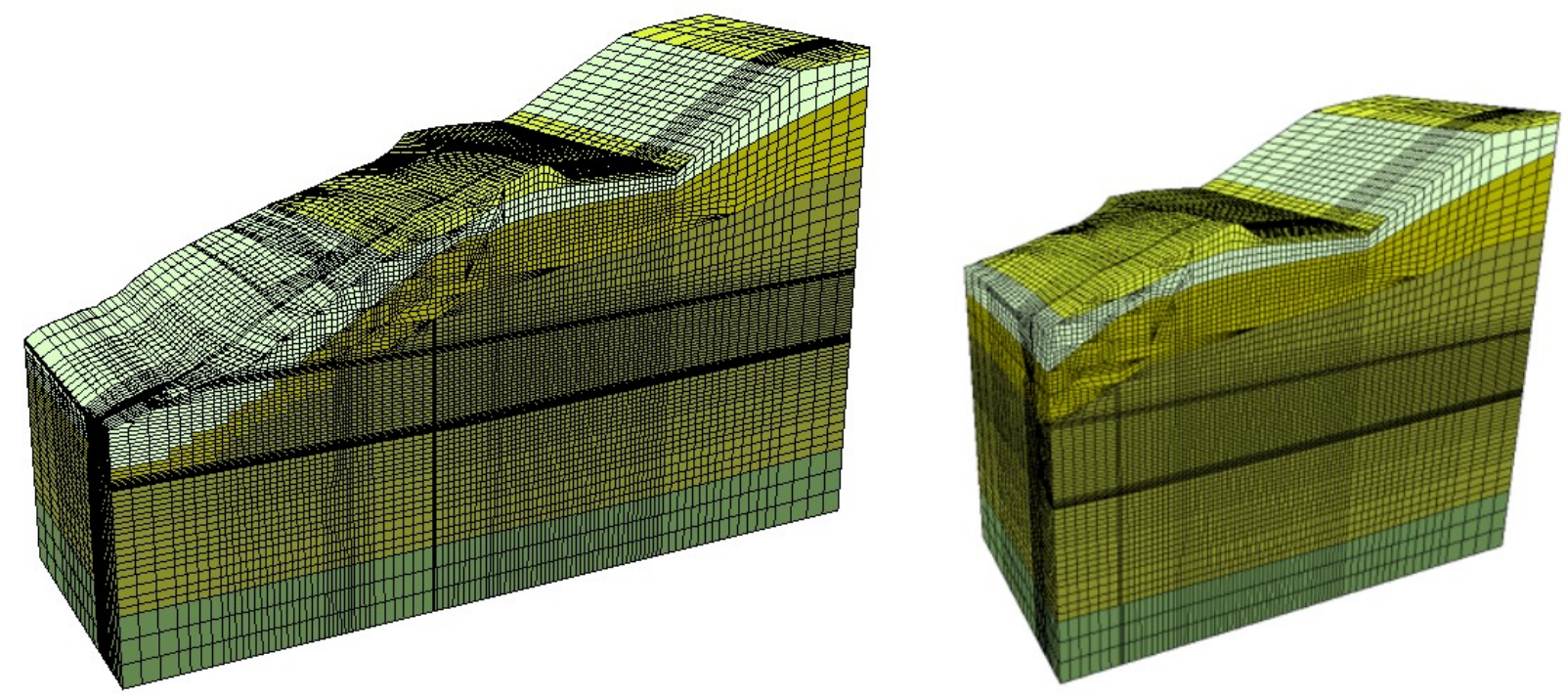

Figure 6. Large (left) and medium (right) size FEM model.
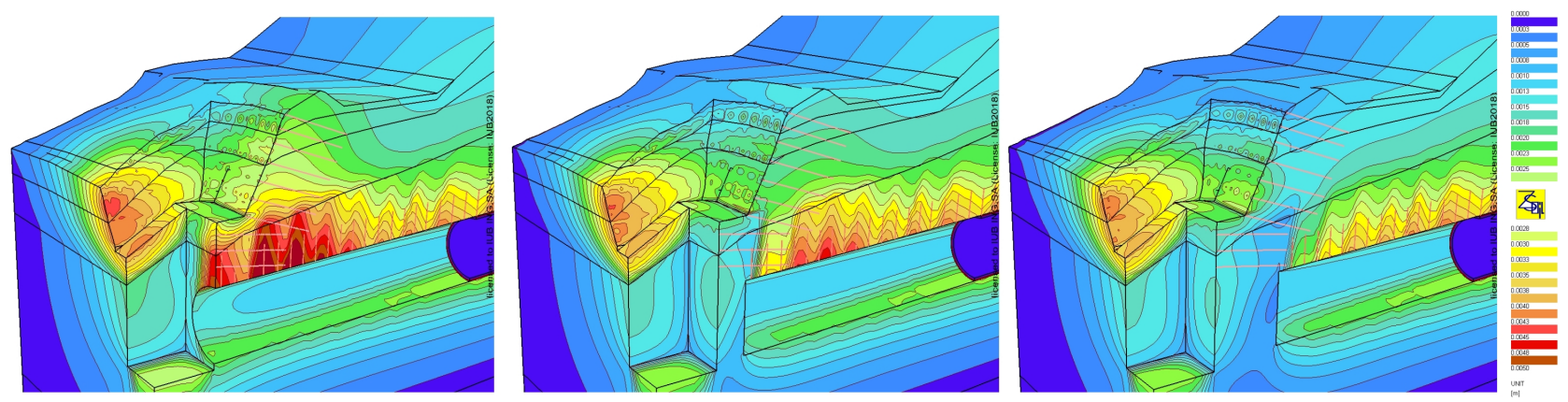

FiguRE 7. Increase of SLS displacements during boring of the gallery (from right to left); max. displacement (brown colour) is $5 \mathrm{~mm}$ with contours $0.2 \mathrm{~mm}$ apart. 

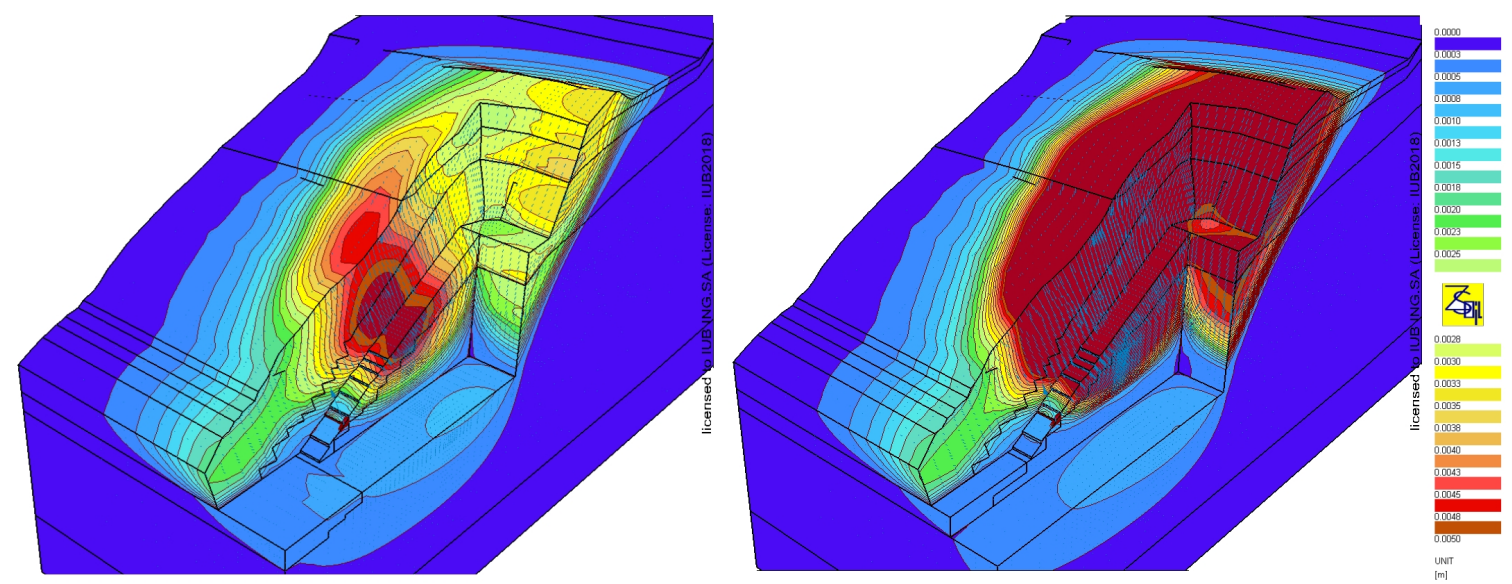

Figure 8. Beginning failure of pit at the last-but one excavation step (left), loss of convergence during the last excavation step (right); colours of abs. displacements as before.
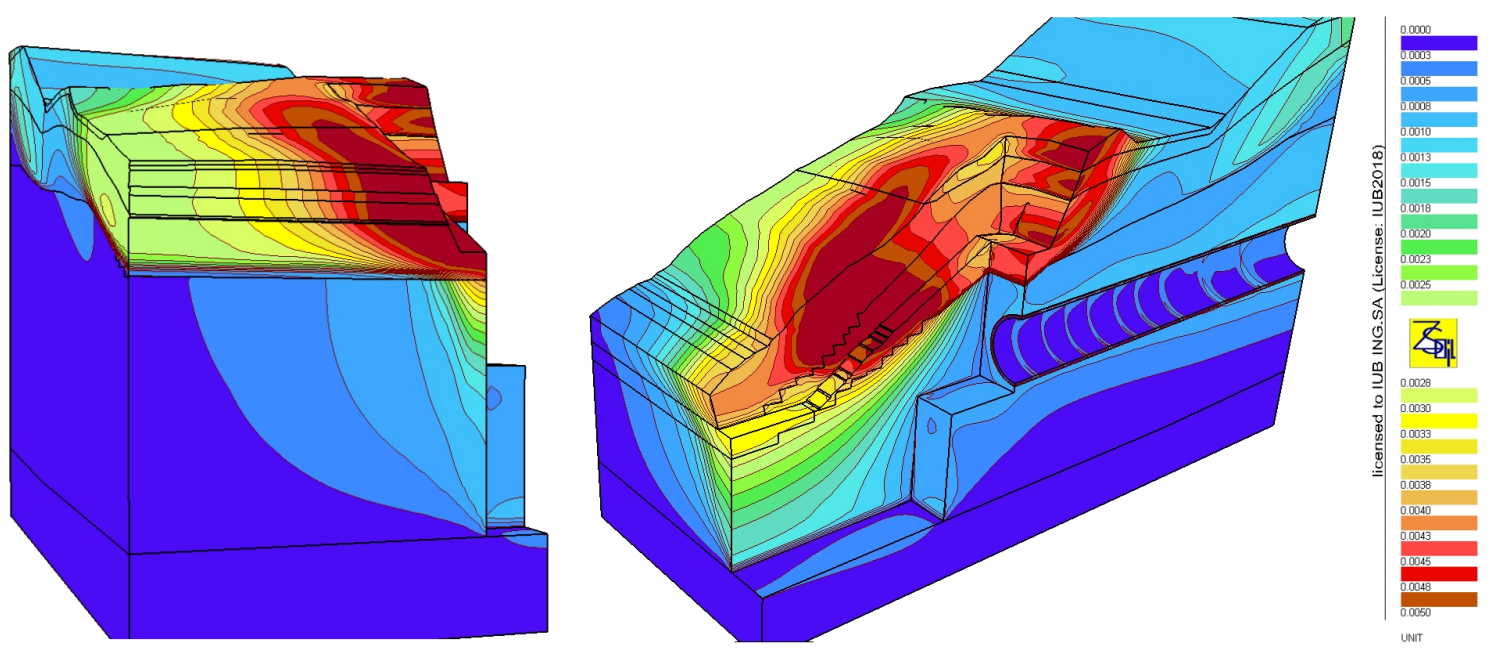

Figure 9. Slip failure of the weathered OSM in $\varphi$-c reduction for the final state $(\mathrm{FoS}=3.0)$; colours of abs. displacements as before.
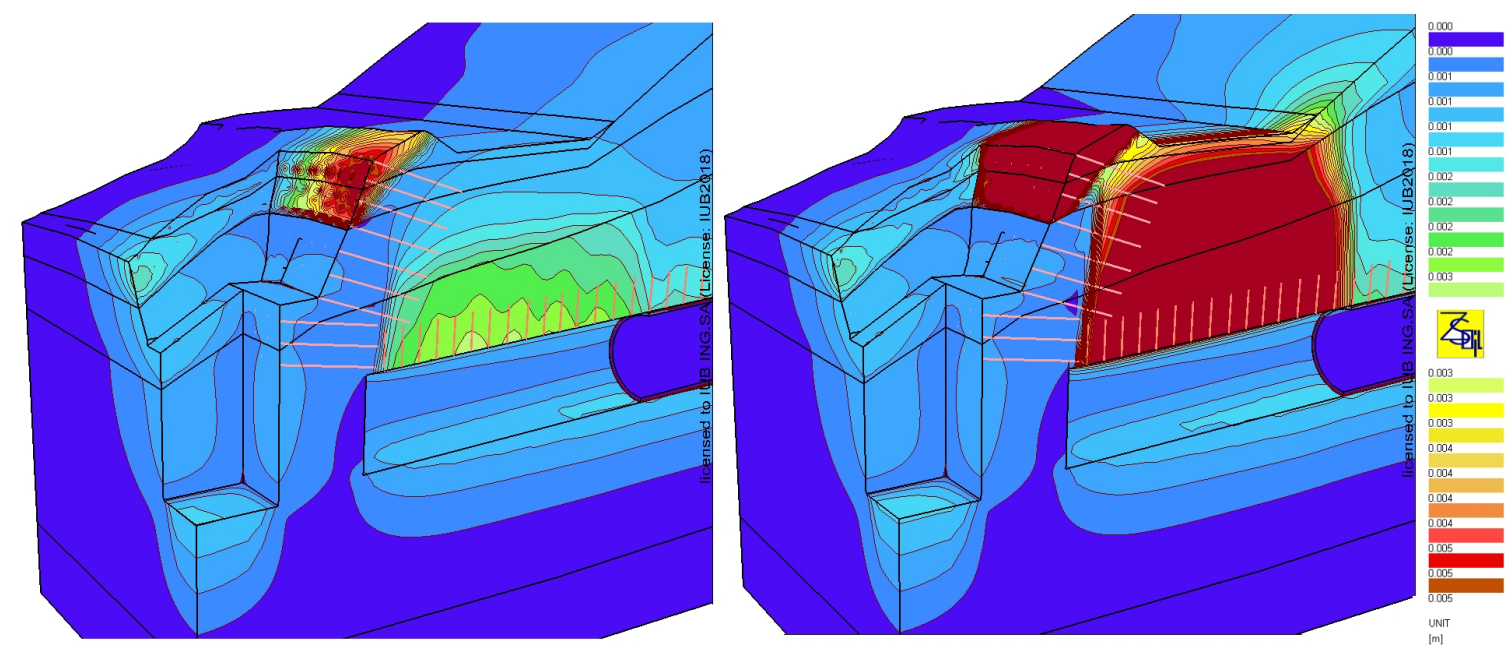

Figure 10. Slope failure of the overburden at $\mathrm{FoS}=1.30$ (left) and $\mathrm{FoS}=1.46$ (right); colours of abs. displacements as before. 

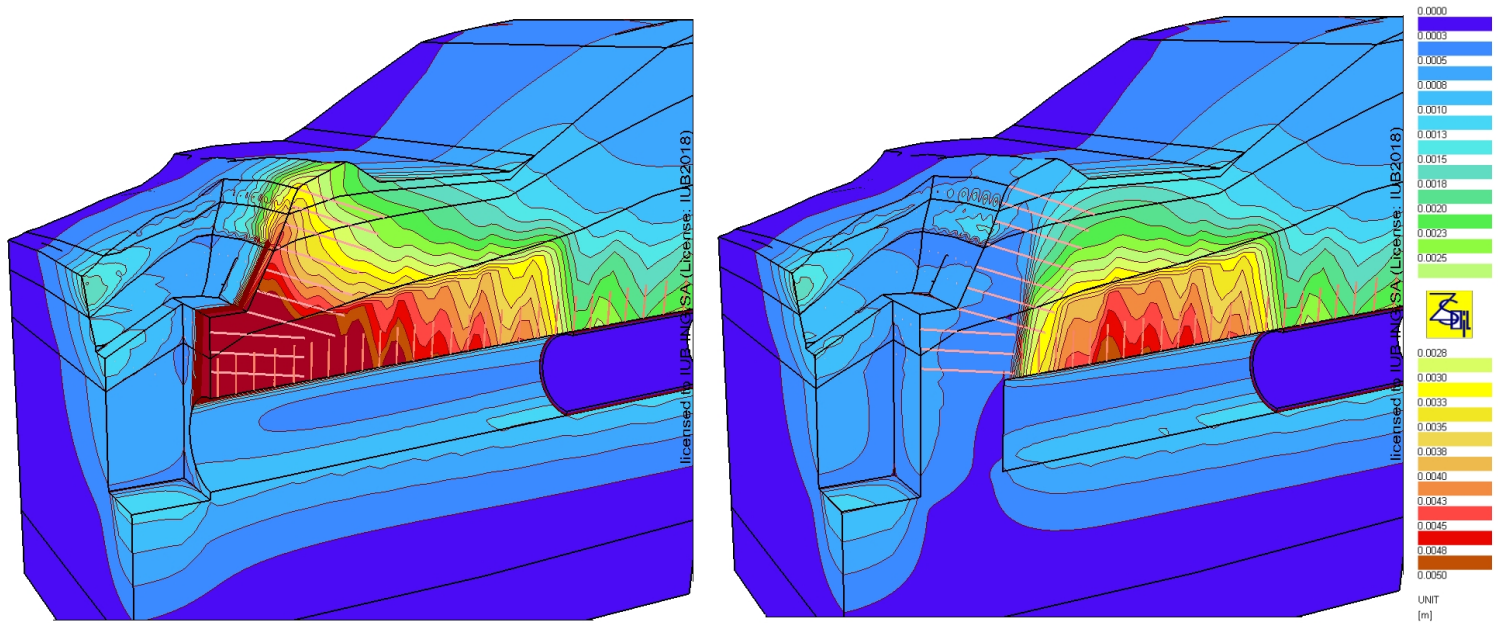

Figure 11. Crown failure in the gallery at $\mathrm{FoSc}=1.18$; colours of abs. displacements as before.

w.r.t. to the lowest values of residual cohesion and consequently the risk to the railway track is deemed too large.

\section{Conclusions Regarding Design}

The numerical analyses for such a wide spread of rock parameters proved quite tricky. Although deformations in the serviceability limit state do not at all look critical, the sensitivity to residual values is too large - the more as seepage and visco-plastic effects are neglected - to take the risk of the gallery staying unlined until the TBM is drawn into the construction pit for disassembly. As a consequence a counter-drive is suggested which extends from the portal wall until right behind the rail-way tracks and will support the ground by a pipe canopy on horse-shoe shaped steel arches. Moreover, additional post-tensioned anchors will be installed in the portal wall as a measure of precaution against the two hazard scenarios outlined in Chapter 3.

\section{ACKNOWLEDGEMENTS}

This contribution is dedicated to Prof. Marta Doležalová, who had first invited me to Prague to give a presentation on joint elements back in 1992 .

\section{REFERENCES}

[1] D. Vischer. Die Geschichte des Hochwasserschutzes in der Schweiz. Bundesamt für Wasser und Geologie, BWG, Bern, 2003. Berichte des BWG, Serie Wasser, Nr. 5, Online, available from: https://www.swv.ch/wp-content/uploads/2018/04/ Geschichte-des-Hochwasserschutzes_BWG.pdf

[2] IUB Engineering AG. References, 2019. Online, available from: https://www.engineering-group.ch/ en/references/projekte/detail/ lake-thun-flood-protection-relief-tunnel.html.

[3] AWEL. Hochwasserschutz an Sihl, Zürichsee und Limmat - Synthesebericht. Zurich, 2015, online, available from: https://awel.zh.ch/internet/ baudirektion/awel/de/wasser/hochwasserschutz/ hochwasserschutz_zuerich.html.

[4] T. Zimmermann, A. Truty, K. Poddles. Numerics in geotechnics and structures, $1985-2015$. Online, available from: http://www.zsoil.com/publications/ ZsoilDay2015_Book.pdf. 